\title{
Keselarasan Lagu dengan Fungsi Pocapan dalam Pertunjukan Wayang Lakon Sudhamala
}

\section{Tatik Harpawati ${ }^{1}$}

Jurusan Pedalangan, Fakultas Seni Pertunjukan, Institut Seni Indonesia Surakarta

\author{
G.R. Lono L. Simatupang, Timbul Haryono, dan Sri Hastanto \\ Prodi Pengkajian Seni Pertunjukan dan Seni Rupa, Sekolah Pascasarjana, \\ Universitas Gadjah Mada Yogyakarta
}

\begin{abstract}
ABSTRAK
Garap pocapan merupakan bagian dari garap catur dalam pertunjukan wayang kulit purwa. Pocapan diiringi oleh grimingan gender di semua wilayah pathet. Penelitian ini memfokuskan pada keselarasan lagu dengan fungsi pocapan dan kaitannya dengan makna pilihan kata sebagai pendukung suasana yang ditampilkan dalam suatu adegan lakon Sudhamala. Tujuan penelitian ini adalah mendeskripsikan iringan yang menyertai pocapan keterkaitannya dengan fungsi pocapan dan menganalisis kesesuaiannya dengan makna kata dan suasana yang ditampilkan dalam sebuah adegan. Permasalahan tersebut dikaji secara tekstual dengan pendekatan struktur. Berdasarkan penelitian disimpulkan bahwa iringan yang menyertai pocapan disesuaikan dengan wilayah pathet dan makna kata yang dipilih. Makna kata dalam pocapan juga disesuaikan dengan suasana yang ditampilkan dalam sebuah adegan. Antara iringan, makna kata pocapan, dan suasana dalam adegan terdapat keselarasan untuk mendukung satu kesatuan fungsi pertunjukan secara keseluruhan dalam lakon Sudhamala.
\end{abstract}

Kata kunci: karawitan pedalangan, pocapan, pathet, Sudhamala

\begin{abstract}
Song Harmony with Pocapan Function on the Performance of Lakon Sudhamala. Garap pocapan is a part of garap catur in wayang kulit purwa. Pocapan uses grimingan gender accompaniment in all pathet areas. The problem of this discussion include how the compatibility of lagu (notation) and the function of pocapan is, as well as its relationship with the words chosen as the atmosphere support presented in a scene of lakon Sudhamala. The discussion is supposed to describe the pocapan accompaniment related to its function and also analyze its compatibility with the meaning of the words chosen. the two thing, then, are observed relating to their compatibilities with the atmosphere presented in a scene of lakon Sudhamala. The problem is analized textually with the structural approach. Based on the approach, it can be found that pocapan accompaniment is suited to pathet areas and the meaning ofthe words chosen. The word meaning in pocapan is also suited to the atmosphere presented in a scene. There is a harmony between the accompaniment, the meaning of the words chosen, and the atmosphere of the scene in order to support the function of the whole performance of lakon Sudhamala.
\end{abstract}

Keywords: music for wayang, pocapan, pathet, Sudhamala

\section{Pendahuluan}

Seni pertunjukan wayang lazim disebut pakeliran atau pedalangan. Sebagaimana seni pertunjukan, seni pedalangan memiliki bahan baku yang berupa soft material atau materi nonfisik sebagai bahan dasar untuk digarap. Bahan dasar ini dinamakan medium. Di jagad pedalangan, terdapat

Alamat korespondensi: : Jurusan Pedalangan, ISI Surakarta. Jln. Ki Hadjar Dewantara, Jebres, Surakarta. E-mail: tatwati@yahoo.com 
empat macam medium, yaitu bahasa, suara, gerak, dan rupa. Ungkapan melalui bahasa dapat berupa dialog (ginem) atau monolog (ngudarasa) dan deskripsi atau narasi dalang, meliputi janturan dan pocapan. Medium suara adalah bahan baku yang berupa wacana, vokal dalang, maupun karawitan pakeliran. Medium gerak merupakan gerak wayang, adapun medium rupa mencakup tampilan bentuk, warna, dan karakter boneka wayang (Suyanto, 2007).

Keempat medium pedalangan diolah ke dalam unsur-unsur pakeliran, yang meliputi (1) catur terdiri atas janturan, pocapan, dan ginem; (2) sabet terdiri atas cepengan, tanceban, bedholan, entasentasan, dan solab); dan (3) karawitan pedalangan terdiri atas gending-gending, tembang, sulukan, dhodhogan, dan keprakan (Sumanto, 2007). Antara unsur yang satu dengan unsur lainnya mempunyai fungsi yang saling berkait dan saling mendukung, baik secara teknis maupun estetis dalam satu kesatuan bentuk sajian suatu lakon pedalangan (Suyanto, 2007). Dalam sebuah sajian lakon, masing-masing dalang memiliki kemampuan yang berbeda-beda dalam mengolah unsur-unsur tersebut. Kemampuan dalang itulah yang menjadikan berbobot atau tidaknya sebuah sajian pakeliran. Seorang pelantun tembang (dapat juga dalang) dapat memancarkan rasa estetis tentu sudah mengalami perjalanan yang cukup panjang, sehingga menguasai berbagai materi garap, memiliki ketrampilan teknik vokal, mampu membangun pola dan keselarasan serta memiliki daya batiniah (Suyoto, Haryono, \& Hastanto, 2015). Kajian keselarasan iringan dengan fungsi pocapan difokuskan pada sajian Ki Nartasabda. Seorang dalang yang kondang pada tahun 19781980-an. Ki Nartasabda adalah dalang yang pandai di bidang catur, dengan menonjolkan unsur persajakan dan perumpamaan (Sumanto, 1990: 105-110). Gaya Ki Nartasabda yang menonjol, yaitu pada pemanfaatan unsur-unsur bunyi, yang meliputi purwakanthi swara, basa, dan sastra. Kemunculan unsur bunyi ini sangat dominan dan bervariasi dalam janturan, pocapan, dan ginem (Harpawati. 2005: 231). Atas dasar alasan inilah maka pocapan sajian Ki Nartasabda dipilih dalam pembahasan ini.
Pocapan berisi pencandraan yang merupakan narasi dalang. Pada umumnya, pocapan menceritakan peristiwa yang sudah, sedang, dan akan berlangsung tanpa diiringi gending sirepan (Sumanto, 2003: 318 dan Suyanto, 2007:14), serta biasanya hanya diiringi grimingan gender, dhodhogan dan atau keprakan (Kuwato, 2001:141). Ditinjau dari bentuknya, pocapan terdapat dua macam, yaitu pocapan baku dan blangkon. Pocapan baku, yaitu narasi yang menceritakan suatu peristiwa berkaitan langsung dengan konteks lakon. Contoh: pocapan peralihan adegan, penggambaran suasana batin tokoh, dan sebagainya. Pocapan blangkon, adalah narasi yang menceritakan suatu keadaan atau peristiwa berupa bahasa klise yang berlaku umum dan tidak berkait langsung dengan konteks lakon. Contoh: pocapan gara-gara, abur-aburan Gathotkaca, padupan, dan sebagainya (Suyanto, 2007: 15). Kedua jenis pocapan itu, digunakan dalang sesuai dengan kebutuhan dalam sebuah sajian lakon secara keseluruhan.

Penelitian ini memfokuskan pada keselarasan iringan dengan fungsi pocapan dan kaitannya dengan makna pilihan kata sebagai pendukung suasana yang ditampilkan dalam suatu adegan lakon Sudhamala. Tujuan penelitian ini adalah mendeskripsikan iringan yang menyertai pocapan keterkaitannya dengan fungsi pocapan dan kesesuaiannya dengan makna kata yang dipilih.

Mengingat pocapan adalah bagian dari teks pertunjukan lakon Sudhamala yang memiliki fungsi dalam kesatuan struktur pembentuk lakon maka kajian secara tekstual dipilih untuk kemudian dianalisis dengan pendekatan struktur. Paradigma tekstual memandang sebuah karya seni sebagai sebuah teks yang dapat dibaca, diberi makna, ataupun dideskripsikan strukturnya (Soedarsono, 1999: 69). Untuk dapat mengetahui fungsi pocapan dalam kesatuan lakon, perlu dilihat fungsinya dalam kesatuan struktur.

Struktur secara umum diartikan sebagai cara sesuatu disusun atau dibangun; susunan; bangunan (Shadilly, 2001: 1092). Konsep struktur dalam tataran karya sastra diartikan keseluruhan yang anasir-anasir atau bagian-bagiannya masingmasing berjalinan. Sementara, konsep struktur dalam tataran sistem sastra adalah sebuah sistem 
yang terdiri atas sejumlah anasir, yang di antaranya tidak satu pun dapat mengalami perubahan tanpa menghasilkan pembahasan dalam semua anasiranasir lain (Teeuw, 1984: 140-141) Struktur dalam karya sastra adalah keutuhan yang terorganisir (Fokkema, D.W. \& Elrud Kunne-Ibsch, 1998: 35). Keseluruhan struktur berarti masing-masing bagiannya dan sebaliknya, masing-masing bagian berarti keseluruhan yang ini dan bukan keseluruhan yang lain. Masing-masing unsur memiliki fungsi khas yang melaluinya setiap unsur dihubungkan dengan keseluruhan dan fungsi-fungsi dan kesalingberkaitan tunduk pada proses perubahan (Fokkema, D.W. \& Elrud Kunne-Ibsch, 1998: 4445). Pocapan merupakan bagian dari unsur-unsur pakeliran. Pakeliran memiliki medium lebih dari satu atau ganda yang dapat dilihat sebagai teks, yaitu berwujud bahasa, suara, rupa, dan gerak. Bahan baku tersebut mutlak harus ada, jika tidak ada maka dalang tidak dapat berbuat apa-apa. Bahan baku tersebut satu dan lainnya merupakan satu kesatuan yang utuh, saling menunjang dan melengkapi. Masing-masing unsur mempunyai arti dan fungsi sendiri-sendiri yang tidak mungkin digantikan oleh lainnya (Murtiyoso, 2007: 3). Dapat dikatakan bahwa jalinan masing-masing unsur sangat erat dan apabila salah satu unsur tidak berfungsi maka akan mengganggu fungsi unsurunsur lainnya. Demikian juga dengan pocapan, yang kehadirannya terkait erat dengan fungsinya dalam sebuah kesatuan struktur pakeliran secara utuh.

\section{Fungsi Pocapan}

Pocapan memiliki fungsi secara teknik dan estetik. Secara teknik, pocapan berfungsi sebagai sarana untuk memberikan penjelasan kepada penonton tentang hal yang sudah, sedang, maupun akan terjadi. Secara estetik, pocapan berfungsi sebagai pendukung atau pembentuk suasana suatu peristiwa (Suyanto, 2007: 15). Pocapan merupakan unsur pembentuk lakon yang berperan antara lain memberi gambaran setting tempat (situasi kondisi tempat terjadinya peristiwa lakon), setting suasana, yaitu suasana adegan, serta deskripsi peristiwa yang sudah terjadi, sedang, dan/atau akan terjadi (Sumanto, 2007: 50). Fungsi pocapan ini disesuaikan dengan wilayah pathet, makna syair, dan lagu grimingan gender.

Pembagian wilayah pathet 6 (nem), 9 (sanga) dan manyura berpengaruh terhadap makna kehadiran pocapan. Dalam wilayah pathet 6 (nem), pada umumnya banyak dinarasikan pocapan blangkon, demikian juga pada wilayah pathet 9 (sanga). Akan tetapi, pada wilayah pathet manyura akan banyak dinarasikan pocapan baku. $\mathrm{Hal}$ itu, terkait dengan dramatisasi lakon secara keseluruhan. Pada wilayah pathet 6 (nem), dramatik lakon masih berkadar rendah kemudian meningkat pada pathet 9 (sanga) dan mencapai klimaks pada pathet menyura (Sumanto, 2003:319-320). Dramatisasi pocapan dapat dilihat pada makna syair pocapan yang akan menyesuaikan dengan wilayah pathet.

\section{Teknik Penyuaraan Pocapan}

Konsep dasar penyuaraan pocapan adalah nuksma, artinya teknik dan lagu penyuaraan dapat sejiwa dengan isi serta suasana pocapan yang diucapkan. Dalam menyuarakan pocapan perlu mempertimbangkan ngeng atau ulon gendhing grimingan gender agar ritme, diksi, volume, dan nada lagu pocapan dapat menyatu dengan ulon grimingan gender (Sumanto, 2007:75-76). Lagu grimingan gender yang digunakan dalam pocapan disesuaikan dengan wilayah pathet.

Dalam pedalangan, pathet merupakan sistem pembagian waktu yang terkait dengan lama waktu pertunjukan pada masing-masing pathet. Pembagian itu terdiri atas pathet 6 (nem) (berkisar antara pukul 21.00 - 24.00), pathet 9 (sanga) (berkisar antara pukul $24.00-03.00$ ), dan pathet manyura (berkisar antara pukul 03.0006.00). Dalam perkembangannya, pakeliran gaya Surakarta tidak lagi ketat mengikuti aturan tersebut (Sumanto, 2003:311-312). Dalam konteks pertunjukan wayang, ruang atau wilayah pathet dibentuk dan dipertahankan oleh suara dalang, gending, dan permainan instrumen gender (Yogyakarta: genukan; Surakarta: grimingan). Pada saat gending dan gamelan tidak berbunyi, ruang atau wilayah pathet dibentuk dan dipertahankan 
oleh sulukan, pocapan, dan genukan atau grimingan gender (Prasetya, 2012). Dengan demikian, pocapan dan grimingan gender dapat digunakan untuk mengetahui wilayah pathet pada saat pertunjukan berlangsung.

Berdasarkan pembagian wilayah pathet, lagu grimingan gender untuk mengiringi pocapan dalam pathet 6 (nem) adalah suasana 6 (nem) yang jatuh pada seleh 6 (nem); pathet 9 (sanga) jatuh pada seleh 1 (siji); dan pathet manyura jatuh pada seleh 3 (telu). Lagu grimingan gender seperti itu dibunyikan terus, diwiletke sesuai dengan ketrampilan penggender (Wawancara Jaka Rianto, 10 Nopember 2015).

Pocapan kadang-kadang juga diiringi bunyi keprakan. Keprakan dalam pertunjukan wayang gaya Surakarta dibedakan dengan dhodhogan. Keprakan dihasilkan oleh bunyi keprak, yaitu susunan empat plat logam masing-masing bernada $6,2,3$, dan 1 yang digantungkan pada kotak wayang. Bunyi keprakan diperoleh ketika dalang memegang cempala tangan atau kaki yang dipukulkan pada keprak tersebut. Sementara, bunyi dhodhogan diperoleh dari cempala tangan yang dipukulkan pada kotak wayang (Putra, Prasetya, \& Sunyata, 2014). Keprak yang digunakan untuk mengiringi pocapan akan dipukul dengan irama nyisir dan apabila suasana pocapan menjelang klimaks maka keprakan akan dipukul dengan irama ngganter. Dhodhogan yang digunakan untuk mengiringi pocapan, yaitu mengggunakan irama banyu tumetes, cempala dipukulkan ke kothak secara tunggal dengan tekanan pelan, lirih, atau keras sesuai dengan suasana pocapan yang ditampilkan (Wawancara Sudarsono, 25 Nopember 2015).

\section{Keterkaitan Fungsi Pocapan dengan Pathet, Makna Syair, dan Lagu}

Bahasa pedalangan adalah bahasa seni sebagai ungkapan jiwa atau ungkapan pengalaman jiwa. Dalang tidak sekedar mengucapkan kata-kata tetapi harus mengerti dan memahami makna kata serta tujuan kata itu diucapkan. Pada prosesnya memang berupa hafalan tetapi kemudian dihayati untuk kemudian diungkapkan agar dapat menimbulkan rangsangan rasa hayatan (Sumanto, 2007: 66). Makna dalam hal ini, yang dimaksud adalah makna linguistik dan nonlinguistik. Secara linguistik, makna kata dapat dilihat dari hubungan antara kata dengan kata, kalimat, dan wacana. Makna nonlinguistik dapat diperoleh dari hubungan antara kata dengan barang atau hal. Makna linguistik dilihat dari susunan leksikal dan gramatikalnya sehingga diperoleh makna denotatif dan konotatif. Makna kata kadangkadang juga perlu dilihat berdasarkan wacana secara keseluruhannya (Djajasudarma, 1993: 5). Makna linguistik adalah lapis literer yang mempunyai arti harafiah. Sementara, pocapan adalah suatu teks jenis sastra yang struktur kalimatnya tidak mengikuti aturan baku. Teks pocapan termasuk jenis teks pertunjukan yang dibuat dengan mempertimbangkan karakter khusus, di antaranya menggunakan ikatan persajakan, panjang pendek suku kata, pilihan kata yang berbeda dari bahasa sehari-hari, mempertimbangkan guru lagu, guru wilangan, bahkan matra dan ritme (Santosa, 2002: 20-21). Hal itu, menunjukkan bahwa makna cakepan (pocapan) dan lagu tidak dapat dipisahkan, artinya terdapat kesesuaian antara kesan rasa yang ditimbulkan oleh lagu dengan kesan suasana yang dibangun oleh kalimat cakepan (pocapan) (Sudarko, 2013: 59). Makna-makna tersebut dilihat dalam konteks pertunjukan sebagai sebuah struktur yang mendukung makna lakon secara keseluruhan.

Sebelum membahas keterkaitan fungsi pocapan, pathet, makna syair, dan lagu terlebih dahulu disajikan balungan lakon Sudhamala. Hal itu, dimaksudkan untuk melihat kedudukan pocapan dalam konteks keutuhan lakon Sudhamala.

\section{Balungan Lakon Sudbamala}

Lakon Sudhamala mengisahkan Dewi Uma yang dikutuk menjadi raseksi oleh Bhatara Guru karena telah berselingkuh. Dewi Uma dalam wujud raseksi, yaitu Dewi Durga bertempat tinggal di Setra Gandamayit. Dewi Durga dapat kembali ke wujud aslinya setelah diruwat oleh Sadewa, bungsu dari Pandawa. Berikut balungan lakon Sudhamala sajian Ki Nartasabda.

Pathet Nem berisi:

1. Adegan Jejer Kahyangan Jonggring Saloka. Bhatara Guru mengadakan pertemuan istana 
yang dihadiri Narada, Dewa Indra, dan lain-lain. Bhatara Guru ingin mendapatkan penjelasan terkait dengan pertanda buruk yang dia lihat di langit dan bumi. Semua Dewa dimintai pendapat dan pendapat dari Naradalah yang dituruti, yaitu memohon petunjuk kepada Sang Hyang Wenang. Keterangan dari Sang Hyang Wenang, bahwa Dewi Uma, istri Bhatara Guru telah berselingkuh dengan Dewa Siwa. Bhatara Guru marah dan mengutuk Dewi Uma menjadi seorang raseksi bernama Dewi Durga. Tempat tinggal Dewi Durga di Setra Gandamayit dan membawahi semua makhluk halus. Dewi Durga akan kembali pulih apabila telah diruwat oleh Sadewa.

2. Adegan di tepi kolam Tirta Kamandanu. Sang Hyang Giripati/Guru sedang mandi dan dikelilingi para bidadari. Bhatara Citrasena dan Citrarata mengintip perilaku mereka. Bhatara Guru mengetahui perbuatan mereka dan mengutuknya menjadi raksasa. Nama mereka diganti dengan Kalantaka dan Kalanjaya. Mereka diharuskan mengabdi ke Hastina dan menuruti semua perintah Prabu Duryudana. Mereka bisa kembali ke wujud asalnya setelah bertemu dengan Sadewa.

3. Adegan Negara Ngastina. Duryudana dihadap Durna, Sengkuni, dan Karna. Mereka membicarakan taktik untuk membinasakan Pandawa dalam perang Bharatayuda. Di tengahtengah pembicaraan, Kartamarma datang dan memberithukan adanya dua raksasa yang ingin menghadap Duryudana. Kedua raksasa, Kalantaka dan Kalanjana bermaksud membantu Kurawa untuk mengalahkan Pandawa. Duryudana menyetujui permintaan kedua raksasa itu. Kedua raksasa berangkat mencari Pandawa. Secara sembunyi-sembunyi, Karna dan Sengkuni mengikuti mereka.

4. Adegan di medan Kurukasetra. Gathutkaca sedang memeriksa medan Kurukasetra. Setyaki berperang dengan Kartamarma. Gathutkaca berperang melawan Kalantaka.

5. Adegan Budhalan-Kapalan. Kedatangan raksasa Kalantaka dan Kalanjana membuat suasana jadi kacau, kemudian Samba dan Setyaki berniat melaporkannya kepada Pandawa.
Pathet Sanga berisi:

1. Adegan gara-gara. Menampilkan adegan humor antara Petruk dan swarawati.

2. Adegan Alas-alasan. Raden Abimnyu diikuti oleh punakawan Semar, Gareng, Petruk, dan Bagong. Abimanyu bermimpi, Pandawa sedang bepergian tetapi Sadewa justru sedang sendiri naik perahu dan diterjang ombak besar. Abimanyu pergi ke Ngamarta.

3. Adegan Cakilan. Di tengah perjalanan Abimanyu bertemu dengan Cakil dan mereka berperang. Cakil terbunuh. Abimanyu berperang melawan para raksasa.

\section{Pathet Manyura berisi:}

1. Adegan di Setragandamayit. Dewi Kunti prihatin mendengar Kalantaka dan Kalanjana dapat mengalahkan anak-anak Pandawa. Dia berniat memohon kepada Hyang widhi dan todak terasa sampai di hutan Setragandamayit. Dewi Durga menemuinya dan bersedia membantu menyelesaikan permasalahan Pandawa asal Dewi Kunti mempersembahkan Sadewa kepadanya. Kunti tidak setuju dan pergi meninggalkan Dewi Durga. Jin Kalika diperintah oleh Dewi Durga untuk merasuki tubuh Dewi Kunti.

2. Adegan Ngamarta. Para Pandawa kebingungan mencari keberadaan Dewi Kunti, Kresna datang menemui pandawa. Tiba-tiba mereka dikejutkan dengan kedatangan Kunti yang sudah kerasukan jin kalika. Kunti menculik Sadewa.

3. Adegan hutan Setragandamayit. Jin Kalika terpelanting dari tubuh Dewi Kunti karena merasa panas. Jin Kalika merayu Sadewa agar mau menjadi suaminya. Jin Kalika tidak dapat menakhlukkan sadewa dan akhirnya melapor kepada Dewi Durga.

4. Adegan Kahyangan. Bhatara Guru merasa kasihan melihat Sadewa yang sedang diikat di bawah pohon gurda oleh jin Kalika. Bhatara Guru merasuki tubuh Sadewa.

5. Adegan ruwat. Dewi Durga tidak berdaya di depan Sadewa. Pada saat jin Kalika melaporkan bahwa Sadewa tidak mau menjadi suaminya, Durga marah dan menemui Sadewa. Akan tetapi, ketika Durga sampai di hadapan Sadewa, ia melihat ada singgasana Bhatara Guru di atas kepala Sadewa, kemudian Durga menyembah 
di hadapan Sadewa. Durga memohon ampun kepada Bhathara Guru. Sadewa yang dirasuki Bhatara Guru mengampuni Dewi Durga dan meruwatnya. Sadewa mengunyah kinang dan meludahi mbun-mbunan Dewi Durga serta mengucapkan mantram sakti. Durga berhasil diruwat dan kembali menjadi Dewi Uma. Bhatara Guru keluar dari tubuh Sadewa dan pergi ke kahyangan bersama Dewi Uma. Sepeninggal Bhatara Guru dan Dewi Uma, Pandawa datang menemui Sadewa. Melaksanakan pesan Bhatari Uma, Sadewa pergi ke Prangalas menemui Begawan Tambrapeta.

6. Adegan Prangalas. Resi Tambrapeta dihadap kedua putrinya dan para abdi. Tiba-tiba mereka kedatangan Nakula, Sadewa, dan Semar. Nakula dan Sadewa menikahi anak Resi Tambrapeta, Soka dan Pradapa. Semar menikahi Nini Thowok. Raksasa Kalantaka dan Kalanjana datang minta diruwat oleh Sadewa. Sadewa berhsil meruwat mereka dan kembali menjadi Dewa Citrasena dan Citrarata. Karena berhasil meruwat mereka, Dewa Citrasena menganugerahi Sadewa dengan nama Raden Sudamala.

7. Adegan Tayungan. Setelah Dewa Citrasena dan Citrarata kembali ke kahyangan. Sadewa melihat Werkudara berperang melawan Dursasana. Setelah Dursasana kalah, Werkudara tayungan. Kresna mengajak werkudara mengheningkan cipta memohon kepada jawata agar selamat tiada halangan suatu apapun.

\section{Tancep kayon}

\section{Pocapan dalam Pathet 6 (nem)}

Bhatara Guru memohon petunjuk kepada sang Hyang Wenang karena adanya pertanda buruk yang terjadi di kahyangan. Sikap semedi Bhatara Guru dan kehadiran Sang Hyang Wenang ke dunia dilukiskan dalam pocapan seperti berikut.

Njegreg kaya tugu pratima mas, Sang Hyang Jagat Giripati cekake raos keclaping cipta sumundhul ing antariksa, sumengka ing kahyangan Awangawang Kumitir, tanggap anggraita Sang Hyang Asih Prana, ya Sang Pada Wenang, ya Sang Hyang Tunggal. Jleg ngejawantah, sumelaking pedhut ing ampak-ampak.
[Berdiri tegak tidak bergerak bagaikan tugu kencana emas, Sang Hyang Jagat Giripati, apa yang dirasakan disampaikan melalui do'a dan dengan cepat menembus sampai langit, sampai ke Awang-Awang Kumitir, mengerti dan paham Sang Hyang Asih Prana, iya Sang Pada Wenang, iya Sang Hyang Tunggal. Dengan tiba-tiba muncul menjelma di dunia. Tersibaklah awan di angkasa].

Pocapan itu dinarasikan Ki Nartasabda dengan iringan grimingan gender dengan lagu atau notasi pada seleh 6 (nem) seperti berikut.

\section{... . 3216}

Berdasarkan konteks dialog yang terjadi antara Narada dan Bhatara Guru dapat dimaknai bahwa konsentrasi saat berdoa yang dilakukan Bhatara Guru sangat tinggi hingga seakan-akan tidak bergerak seperti tugu. Hal itu, membuat do'anya segera sampai dan seketika terkabulkan. Pocapan dengan makna seperti itu menuansakan suasana hening dan diucapkan pada wilayah pathet 6 (nem). Dalam wilayah ini, dramatisasi masih datar namun teknik penyuaraan nuksma dapat dirasakan dari lagu penyuaraan yang sejiwa dengan isi serta suasana pocapan yang diucapkan. Ritme, diksi, volume, dan nada lagu pocapan dapat menyatu dengan ulon grimingan gender yang jatuh pada seleh 6 (nem).

Pocapan selanjutnya dinarasikan $\mathrm{Ki}$ Nartasabda pada saat Bhatara Guru memanggil Batari Uma untuk memberi hukuman karena telah berselingkuh.

Kagyat kadora wekasan esmu glarapan jroning penggalih, Batari Uma dupi piniji angabyantara mangarsa Sang Hyang Jagat Girinata. Kinoyak denya ngrasuk busana, kekandelan tetasike, pinulas-pulas lelathine, kinerik alise, kinethok godhege, linalar-lalar sarirane tambah jenar, ginawe-gawe lelewane, dhasaring satunggaling hapsari ingkang sakedah ewahe sarwa mantesi, gebyar-gebyar kang busana, kasorot ing bagasakara ngantya kaya kasireng lamun pinandeng, dangudangu kaya musna kinedhepake, nanging kaya ngapa ta kagyating manah dupi nedya sumungkem pepadane Sang Hyang Jagat Girinata wekasan tinambuhan, myat jumeneng saking palenggahan Sang Hyang Jagat Giripati amengkeraken ingkang 
garwa Batari Uma. Mula teka mangkana pangudasmaraning panggalih Batari Uma lamun kawijil ing lesan.

[Sangat terkejut hingga membuat hatinya gundah, Batari Uma ketika disuruh menghadap Sang Hyang Jagat Girinata. Segera berbusana, menebalkan bedaknya, memoles bibirnya, membentuk alis, mencukur jambang, melulur badan agar semakin kuning, dibuat-buat polah tingkahnya, pada dasarnya memang bidadari yang semua tingkah polahnya luwes, bersinar pakaiannya, tersorot sinar matahari bagaikan menyilaukan, jika dilihat tanpa berkedip, semakin lama seakan-akan hilang jika mata dikedipkan, tetapi tidak bisa dilukiskan rasa terkejutnya ketika akan menyembah kaki Sang Hyang Jagat Girinata akhirnya kecewa, seketika berdiri sang Hyang Jagat Giripati membelakangi istrinya Batari Uma. Demikianlah kata hati Batari Uma jika dilisankan]

Pocapan itu dinarasikan Ki Nartasabda pada wilayah pathet 6 (nem) dengan iringan grimingan gender dengan lagu atau notasi pada seleh 6 (nem). Nuansa makna dalam pocapan itu adalah lukisan rasa gundah gulana dan rasa keterkejutan seorang istri yang tiba-tiba dipanggil suaminya. Dramatisasi masih datar namun suasana nuksma dapat dirasakan dan nada lagu pocapan dapat menyatu dengan ulon grimingan gender yang jatuh pada seleh 6 (nem).

Pocapan berikutnya melukiskan kegagahan Raden Gathutkaca ketika akan berperang.

Lah punika ta warnane ingkang ndaweg pacak baris ing Kurukasetra, raja mudha ing Pringgadani akekasih Raden Gathotkaca ya Raden Tetuka, Guritna, Purbaya, Senaputra, Harimbiatmaja, deniarsa anganglang Kurukasetra. Ri sang Gatutkaca nedya mahawan gegana ketingal anggana raras glewo-glewo kaya golek kancana bisa ngocap. Wusnya rampung denya matrapake busana sawiji mbaka sawiji tan ana kang kacicir, gya ngrasuk busana wasiat peparinge dewa Caping Basunanda, Kotang Antakusuma miwah Tarumpah Pada Kacerma. Caping Basunanda daya panguwasane ana udan datan kodanan yen panas tan kepanasan. Kotang Antakusuma sayekti bangkit dirgantara tanpa beda ing dhedharatan. Tarumpah Pada Kacerna sayekti walungsungane Sang Hyang Anantaboga dewatane sarpa, daya panguwasane yen lumampah lemah sangar kayu aeng dadi tawa tawar bisoa dadi ngapa.

[Lah inilah wujud yang sedang berbaris di Kurukasetra, raja muda di Pringgodani berjuluk Raden Gathotkaca, iya Raden Tetuka, Guritna, Purbaya, Senaputra, Harimbiatmaja, dia akan memeriksa Kurukasetra. Gathotkaca terbang dan terlihat gagah tinggi besar bagaikan patung emas bisa berbicara. Setelah selesai mengenakan pakaian, satu persatu tidak ada yang terlupa, segera memakai busana wasiat pemberian dewa, yaitu Caping Basunanda, Kotang Antakusuma, dan Tarumpah Pada Kacerma. Caping Basunanda mempunyai kesaktian jika ada hujan maka tidak akan kehujanan dan jika panas maka tidak akan kepanasan. Kotang Antakusuma dapat terbang di langit tiada beda dengan berjalan di darat. Tarumpah Pada Kacerna sungguh merupakan kulit dari walungsungan Sang Hyang Anantaboga, yaitu dewanya ular. Kekuatannya jika berjalan di tanah yang berbahaya maka menjadi netral, pohon yang membahayakan bisa netral, tidak bisa berbuat apa-apa].

Kesan nuksma didapat dari ulon grimingan gender yang jatuh pada seleh 6 (nem). Suasana pathet masih datar maka makna pocapan juga bernuansa datar, yaitu gambaran kegagahan dan kesaktian Gathotkaca sebagai seorang ksatria. Nuansa makna yang terdapat dalam pocapan itu belum menampakkan adanya dramatisasi.

Lukisan keadaan Gathotkaca masih dilanjutkan dalam pocapan seperti berikut.

Sampat busanane wong agung ing Pringgadani gya cancut tali wanda, tali arane acincing, taliwanda cecawetan, ngencengake tali bebadhonge, nglengser celanane, netepake jejamange, ngusap gumbala, miyak simbar jaja, nggedruk pratala ndedel nggayuh ngatariksa kaya kilat thathit sumusuping jaladra.

[Lengkap pakaian Wong Agung di Pringgodani dan segera mengencangkan tali celana, tali badhong, menurunkan celana, menata kumis, mengusap jambang, menyibak bulu dada, memukulkan kaki ke tanah dan terbang ke angkasa bagaikan kilat yang menyusup di awan].

Pocapan itu mempunyai makna kesigapan seorang satria yang bertugas mengamankan 
wilayahnya. Sikap sigap dan siap siaga menuansakan makna berwibawa, pengucapan bernada datar pada wilayah pathet 6 (nem). Nuansa nuksma diperoleh dari ulon grimingan gender yang jatuh pada seleh 6 (nem). Dalam pocapan itu, dramatisasi juga belum tampak menanjak.

Pocapan berikut dinarasikan Ki Nartasabda pada saat menggambarkan Sang Hyang Girinata mandi di sebuah kolam.

\section{Akimplah-kimplah alerap-lerap balumbange Tirta Kamandanu, Sang Hyang Girinata anglugas raga nggebyur ing Tirta Kamandu namung sajuga, nanging ingkang lelados langkung kawandasa para widadari pepingitan para hapsasri pepethingan, ingkang melok-melok wadanane, rompyo- rompyo sesinome, angudup turi gegodhege, wewek payudarane, ngolan-olan janggane, nanggal sepisan alise, kang dhemes lathine, kang arum gandane, waneh-waneh patrape, ana kang angujiwat sarwi anjawat, ana kang saweneh ethok-ethok dhawah ing balumbang, ana ing saweneh api-api glageban ing pamrih supaya tinulungan marang S. H Jagat Girinata, ana saweneh ingkang nglangi wonten ing sangandhaping suku, ana saweneh kang ngujiwat angawe-awe, ana saweneh kang arembyak-rembyak rambute, awit saking drenging kawicaksanan Sang Hyang Jagat Girinata. Sanggya para widadari ingkang lelados siram sadaya tinimbalan wus caket mangarsa.}

[Berombak-ombak air kolam Tirta Kamandanu, Sang Hyang Girinata telanjang mencebur ke kolam Tirta Kamandanu hanya sendirian tetapi yang meladeni lebih dari 40 bidadari pilihan, yang bersinar wajahnya, subur rambut halus di pangkal dahinya, jambang seperti bunga turi yang belum mekar, montok payudaranya, dagu bagai lebah bergantung, alis bagai bulan tanggal satu, manis bibirnya, harum baunya, apalagi tingkahnya, ada yang menggoda sambil menyentuh, ada sebagian yang pura-pura jatuh di kolam, ada yang pura-pura terengah-engah minum air kolam dengan maksud ditolong oleh sang hyang Jagat Girinata, ada yang sebagian berenang di bawah kaki, ada yang menganggu melambaikan tangannya, ada yang mengurai rambutnya, agar semua itu mendapatkan kebijaksanaan Sang Hyang Jagat Girinata. Semua bidadari yang meladeninya diundang dan sudah berada di dekatnya].
Makna pocapan itu melukiskan keadaan yang serba indah dan menyenangkan. Indah jernih air kolamnya dan serba menyenangkan tingkah laku serta rupa bidadari-bidadari yang menggoda Sang Hyang Jagat Girinata. Nuansa makna tersebut dinarasikan padha pathet 6 (nem). Dalam pocapan itu, dramatisasi belum dibangun dan isi pocapan itu akan berkaitan dengan alur lakon pada saat Sang Hyang Jagat Girinata mengutuk 2 dewa, yaitu dewa Citrasena dan Citrarata karena telah berani mengintip saat Sang Hyang Jagat Girinata mandi. Kedua dewa itu dikutuk menjadi raksasa.

Narasi pocapan berikutnya berisi gambaran perilaku raksasa Kalantaka dan Kalanjana sebagai berikut.

Lah ing kana ta wau, lampahing reksasa kekalih wus andharat ing madyapada turut ing dhusunngadhusun sami angangah-angah anjejarah, sarwi keh padesan rumangsa uripre kaya digegabah, kahanane kaya digerasah, raja branane jinarahrayah. Mila kathah ingkang samya ngungsi saka padunungane sowang sowang, tambuh-tambuh kang jinujug. Sinigeg kang ndawek lumaksana, nahan ta ganti kang cinarita, kang ana jroning puraya gung negari Ngastina, ngumandhang malembar saindhenging jagad.

[Lah di sana tadi, perjalanan kedua raksasa sudah sampai ke dunia, menyusuri desa-desa, mereka menjarah, banyak desa yang merasa hidupnya bagai tidak dihargai, keadaan seperti dalam kerusuhan, harta benda dijarah. Oleh karena itu, banyak yang mengungsi dari tempat tinggalnya masing-masing, tidak tahu arah tujuan. Tidak diceritakan lagi yang sedang terjadi, kemudian ganti yang diceritan, yang ada di dalam istana besar negara Ngastina, tersohor di seluruh dunia].

Pocapan bermakna rusuh dan gaduh itu dinarasikan Ki Nartasabda pada pathet 6 (nem) akhir sehingga dramatisasi mulai tampak menanjak walaupun nada grimingan gender tetap jatuh pada seleh 6 (nem).

\section{Pocapan dalam Pathet 9 (sanga)}

Wilayah pathet 9 (sanga) memiliki kadar dramatik agak menanjak dibandingkan dengan 
kadar dramatik pada pathet 6 (nem). Ulon gending grimingan gender dengan lagu atau notasi jatuh pada seleh siji seperti berikut.

\section{. . . . $532 \quad 2 \quad 1$}

Pocapan yang dinarasikan Ki Nartasabda diawali dengan pelukisan suasana pergantian dari siang ke malam hari, seperti berikut.

Sirepe Sang Hyang Arka gumantosing dalu, jroning ratri dereng wonten ingkang cinarita, amung Sang Hyang Candra kang mijil saking pertala arsa amerbawani jagad, dupi tatasing kamantyan dewasane Sang Hyang Arka, nengna wauta wus ngancik gara-gara.

[Memudarnya Sang Hyang Arka berganti menjadi malam, dalam malam belum ada yang diceritakan, hanya Sang Hyang Candra yang muncul dari langit akan menerangi dunia, setelah hilang wujud Sang hyang Arka, demikianlah mulai gara-gara].

Nuansa makna dalam pocapan itu adalah lukisan perubahan suasana menjelang gelap. Pocapan dengan makna sunyi, sepi, dan bulan mulai bersinar dalam gelap seperti itu diucapkan pada wilayah pathet 9 (sanga). Dramatisasi sudah terasa agak meningkat dan suasana nuksma dapat dirasakan dan nada lagu pocapan yang menyatu dengan ulon grimingan gender, yang jatuh pada seleh 1 (siji).

Pocapan berikutnya melukiskan keadaan yang terjadi pada saat gara-gara, seperti berikut.

Gara-gara, apa ta isine gara-gara, bawana sidhem kados banyu ning sampur lebur, ing akasa munya gumaludhug, andhedheri ngakak gugurane arga, gora gurnita kagiri-giri lebur prakempita mangambak-ambak, santer suarane lesus lir pinusus, sindhung riwut magenturan, kumucak mawetu mulat mubal kababal genine Yomani, dres mawur Sang Hyang Riris kartika tinibeng kisma jumlegur jugruk swarane, kawah Candradimuka kaya kinebur, syuh sumamburat ngambara si bleg endhut si bleg daba, menceng wot ogal-agil, rengat sungune lembu Andini, kumitir pethite, ngablak tutuke bathara Anantaboga, pangriking sapi gumarang nganti kaya belah-belahna langit, cagak goncang bale Marakata, kaya jebol-jebola kori lawang sela matangkep, sami sakala geger para dewa-dewi, hapsara-hapsari, widadara-widadari samya ngungsi mring Sang Hyang Rodrapati, sirnaning wewelak sireping kang gara-gara, jumedhuling sanggya repat Panakawan.

[Gara-gara, apakah isi gara-gara, bumi terdiam bagaikan air yang yang teraduk jadi satu, di angkasa terdengar bunyi petir, terdengar gemuruh suara reruntuhan gunung, hancur lebur, angin lesus terus menerus, gaduh tiada henti, teraduk-aduk keluarlah api neraka membumbung tinggi, berhamburan Sang Hyang Riris, bulan jatuh ke laut suaranya bergemuruh, kawah candradimuka bagaikan diaduk, berhamburan tanah liat bercampur batu, tidak lurus lagi jembatan ogal-agil, rapuh tanduk lembu Andini, bergetar ekornya, terbuka lebar mulut bathara Anantaboga, lenguhan sapi bagaikan membelah langit, tiang balai Marakata berguncang, bagaikan terbelah pintu Sela Matangkep, seketika geger para bidadari, mereka mengungsi ke tempat Sang Hyang Rodrapati, hilangnya kegaduhan maka sirnalah gara-gara, kemudian muncul para punakawan].

Pocapan gara-gara itu menuansakan makna keadaan yang gaduh, ribut, menakutkan, dan mencekam. Dramatisasi mulai terlihat pada pocapan itu, yaitu adanya keadaan yang mulai memuncak dan hal itu dinarasikan dalang dengan nuksma selaras dengan ulon grimingan gender yang jatuh pada seleh 1 (siji).

Dramatisasi juga tampak memuncak pada saat Ki Nartasabda menarasikan Abimanyu perang melawan para raksasa dan berhasil membunuhnya. Keadaan itu terlihat di dalam pocapan berikut.

Pating balingkrah kaya babatan pacing kuwandhane para drubiksa nanging sakedhaping netra sirna saking pandulu, wangsul ing ajal kamulane, Wauta sang Bimanyu dupi mulat sirna pepalanging marg, $i$ angawe sanggya repat panakawan kinanthi laju lampahe sinebut sangsaya sengkut, derenging cipta tan nedya kendel lamun dereng prapta kang sinedya, anenggih prajagung negari Ngamarta.

[Berserakan bagaikan cacing, jasad para raksasa tetapi sekejap mata sudah hilang dari pandangan, kembali ke asal mulanya. Demikianlah Abimanyu pada saat melihat sudah hilang penghalang jalannya, melambaikan tangan kepada para punakawan dan semakin dipercepat jalannya, 
dalam batin mengatakan bahwa tidak akan berhenti sebelum sampai tujuan, yaitu kerajaan besar Negara Ngamarta].

Pocapan itu menuansakan makna mencekam, yaitu adanya peperangan dan makna tergesagesa. Dramatisasi terlihat mulai menanjak, ulon grimingan gender yang jatuh pada seleh 1 (siji) nuksma dengan keras lunak, tempo, dan nada suara dalang pada saat menarasikannya.

\section{Pocapan dalam Pathet Manyura}

Wilayah pathet manyura merupakan puncak dramatisasi lakon. Nuansa makna pocapan juga mengandung dramatisasi yang meningkat atau memuncak. Hal itu dilukiskan dalam pocapan berikut.

Wirandungan tindakira sang Bimanyu, candrane kaya taksaka den pidaki pethite, sapecak mangu sapecak kendel tumulih wingking, angentosi lampahing para dasih nalika wus kapengker tebih saka tegal pegagan, laju denya lumaksana, Sinigeg kang lumaksana ing marga, genti ingkang cinarita ingkang ndawek andon lelana, samarga-marga tansah eling dhateng putra-putrane.

Pocapan itu menuansakan makna kebimbangan dan kegelisahan seseorang yang melakukan perjalanan. Pocapan dengan makna bimbang, ragu-ragu seperti itu diucapkan pada wilayah pathet manyura. Dramatisasi terlihat sampai pada puncaknya dan suasana nuksma dapat dirasakan dan nada lagu pocapan yang menyatu dengan ulon grimingan gender, yang jatuh pada seleh 3 (telu) seperti berikut.

\section{. . . ! 653}

Pocapan berikutnya merupakan penggambaran pada saat Dewi Kunti Talibrata sedang bersemedi di Setra Gandamayit.

Tumungkul wadanane Dewi Kunti Talibrata, manthering cipta tan ana kang kasuwun mring jawata mubung jayaning para putra. Denya samadi ing kono maweh perbawa panas, geger saisine wana, sanggya para drubiksa, jarangkong warudoyong, engklek-engklek balung atandhak, wewe janggitan lindhu, nadyan kang ana pagupone warak, kasonging guwa lemah miring padha kontrang-kantring wayang-wuyung wewayangan. Anggraita kang ana kahyangan pasetran Ganda Manyit, jleg dewatane bekasakan anenggih batari Durga.

[Menunduk wajah Dewi Kunti Talibrata, khusuk mengheningkan cipta hanya memohon kepada Dewa bagi kejayaan anak-anaknya. Semedi di tempat itu berpengaruh pada cuaca, yaitu udara menjadi panas yang mengakibatkan seisi hutan kacau. Semua makhluk halus, jrangkong warudoyong, engklek-engklek, balung atandhak, wewe janggitan, walaupun ada di dalam sarangnya, gua, tanah miring, tapi mereka berlari tidak tentu arah. Yang bertahta di Setra Gandamayit merasakan hal itu, yaitu Dewi Durga sebagai ratu makhluk halus menampakkan diri].

Pocapan yang menuansakan makna panas dan kacau balau tersebut dinarasikan Ki Nartasabda pada wilayah pathet manyura. Dramatik lakon terlihat mulai memuncak seiring dengan adanya makna panas dan kacau balau yang diakibatkan adanya orang bersemedi di daerah kekuasaan makhluk halus. Ulon grimingan gender tetap jatuh pada seleh 3 (telu) dan disambung dengan bunyi dhodhogan dan keprakan banyu tumetes tetapi menjadi bertempo cepat pada saat pocapan hampir selesai.

Gambaran rasa panas jin Kalika pada saat merasuki tubuh Dewi Kunti diungkapkan dalam pocapan sebagai berikut.

Raos benter Jim Kalika tunggal sajiwa lan Dewi Kunti, mijil saking gua garba dewi Kunti kacepeng ing astanipun kalih kabuncang tebih, pagedhonganipun sampun tinampi dening para Pandawa, kaya ngapa kageting penggalih sang Sadewa mulat ana jim mengengeh tutuke.

[Panas yang dirasakan Jin kalika pada waktu merasuki tubuh Dewi Kunti memaksa dia keluar dari perut Dewi Kunti, dapat dipegang dengan kedua tangan dan dibuang jauh, dan tubuhnya diterima para Pandawa. Betapa terkejutnya Sadewa melihat ada jin menganga mulutnya].

Pocapan tersebut semakin memperkuat dramatik lakon. Adanya nuansa rasa panas yang dirasakan jin Kalika dan keterkejutan yang dialami Sadewa menjadikan ketegangan permasalahan lakon semakin memuncak. Ulon grimingan gender 
tetap pada seleh 3 (telu) dan diakhiri dengan dhodhogan dan keprakan dalam irama cepat.

Makna suasana semakin mencekam dan dramatisasi memuncak pada pocapan berikut.

Nggramang kang ula dumung sewu teka bareng. Sima singa rong ewu teka bareng, bangsane entupentupan sing gedhene sagerdhu, sumanding sang Sahadewa. Parandene datan miris boten giris, kapara saya tajem pepolatane nganti jelih-jelih jim Kalika angundangi para sato ewadene boten anjalari gigriking manah sang Sadewa. Mula teka mangkana pangudasmaraning driya lamun kawijiling lesan.

[Menjalarlah ular dumung yang berjumlah seribu dan mereka datang bersamaan. Harimau dan singa berjumlah dua ribu dating bersamaan, hewan yang menyengat sebesar pohon gerdu, tetap bersandar sang Sahadewa. Namun demikian, tidak khawatir dan tidak takut, justru semakin tajam penglihatannya sampai menjeritjerit jin Kalika mengundang hewan-hewan tetapi tidak membuat takut Sang Sahadewa. Demikian itu kata hatinya jika dilisankan].

Nuansa makna yang mengetengahkan suasana kemarahan tersebut dinarasikan $\mathrm{Ki}$ Nartasabda dalam wilayah pathet manyura. Ulon grimingan gender mengikuti wilayah pathet yang menuansakan suasana mulai memuncak, konflik terasa menegangkan. Pocapan selanjutnya masih bernuansa penuh kemarahan tetapi sekaligus juga mulai memudar, seperti terlihat berikut.

Sang pandya Batari Durga wus nampi pradule jim Kalika pada sakala duka sinipi, jaja bang mawinga-winga, kumejot padoning lathi, netra kocak ngondar-andir, kerot-kerot kanang waja, idepnya mangala cakra, soring jangga malatulatu, yen ta sinabeting merang sagepel medal dahanane. Nedya amrepeki sanggyaning Sadewa nanging kaya ngapa ngungune penggalih dupi mulat pasundhulaning sang Sahadewa wonten singgangsana adi, inggih menika palenggahane Sang Hyang Jagat Girinata mila ngalumpruk kaya kapuk winastanan.

[Bhatari Durga sudah menerima laporan dari jin Kalika, seketika sangat marah, dilukiskan hati membara, lidah bergetar, mata terbelalak, gigi berbunyi gemeretak, bulu mata tegak, leher menyala bagaikan api yang andaikan tersabet merang pasti akan mengeluarkan api. Dewi Durga segera menemui Sadewa tetapi betapa terkejutnya ketika melihat di atas kepala Sahadewa terdapat singgasana indah, yaitu tempat duduk Sang Hyang Jagat Girinata. Oleh karena itu, Dewi Durga lemas bagaikan kapas].

Dramatisasi yang dilukiskan dalam pocapan tersebut mencapai puncaknya dan kemudian mulai menurun. Suasana itu terlihat dari nuansa makna pocapan, yaitu lukisan kemarahan Dewi Durga dan lukisan ketidakberdayaannya. Pocapan itu dinarasikan Ki Nartasabda pada pathet manyura dengan ulon grimingan gender jatuh pada seleh 3 (telu).

Dramatisasi yang sudah menurun menuju penyelesaian konflik terlihat pada pocapan berikut.

Nyembah sesedhokan sang Pandya Batari Durga dateng sang Sahadewa karana mulat bilih ingkang tunggal sajiwa lan sang Sahadewa menika anenggih Sang Hyang Jagat Girinata. Uma umaripik soring Sahadewa, waneh-waneh kang ginagas reninging manah karasa blak sumilak karana enget warsitane Sang Hyang Jagat Girinata duk inguni, bisa rinuwat saking kacintrakan lamun sampun pinanggih lawan wuragiling Pandawa, satriya ing Bumi Retawu ingkang akekasih Raden Sahadewa mila sumengkaning manah tan kena kinambengan kaya-kaya anjelih sang Pandya Batari Durga.

[Bathari Durga berlutut menyembah Sahadewa karena melihat bahwa yang menyatu sejiwa dengan Sadewa adalah Sang Hyang Jagat Girinata. Uma tunduk di hadapan Sahadewa, tiada lain yang selalu dipikirkan dalam hati sudah terlihat jelas karena ingat pesan Sang Hyang Jagat Girinata waktu dulu, bisa ruwat dari malapetaka apabila sudah bertemu dengan ragil Pandawa, satria dari Bumi Retawu, yang bernama Raden Sahadewa, mangka tiada sabar hatinya bagaikan mau menjerit Sang Batari Durga].

Pocapan tersebut diiringi ulon grimingan gender yang jatuh pada seleh 3 (telu) dan menuansakan makna pasrah dan bahagia. Dramatisasi sampai pada penyelesain yang digambarkan dalam pocapan berikut.

Kocap kacarita nalika samana Sang Sahadewa kang asarira Sang Hyang Jagat Girinata gya 
angganten, wus angganten kinecohken mbunmbunane Bathari Durga nedya angrapal mantram sakti.

[Diceritakan pada waktu itu, Sang Sahadewa yang sudah manunggal dengan Sang Hyang Jagat Girinata segera menginang, setelah menginang kemudian diludahkan ke ubun-ubun Bathari Durga dan segera mengucapkan mantram sakti].

Pocapan itu melukiskan keadaan sudah tenang dan bahagia karena Dewi Durga berhasil diruwat, yaitu dikembalikan ke wujud aslinya. Setelah itu, Dewi Durga berubah menjadi Dewi Uma dan kembali ke kahyangan. Ulon grimingan gender yang jatuh pada seleh 3 (telu) mengiringi Dewi Uma dan Sang Hyang Jagat Girinata menuju kahyangan.

\section{Penutup}

Keselarasan iringan dengan fungsi pocapan dan kaitannya dengan makna pilihan kata sebagai pendukung suasana yang ditampilkan dalam suatu adegan lakon Sudhamala dapat dilihat dari wilayah pathet pada saat pocapan dinarasikan.

Pocapan-pocapan yang dinarasikan $\mathrm{Ki}$ Nartasabda pada wilayah pathet 6 (nem) menuansakan makna suasana hening, gundah gulana, terkejut, sigap, indah, senang, rusuh, dan gaduh. Nuansa makna seperti itu, menandakan bahwa dramatisasi lakon belum tampak dan cerita masih dalam tahap awal timbulnya permasalahan. Akan tetapi, menjelang pergantian pathet, Ki Nartasabda menarasikan pocapan yang menuansakan suasana rusuh dan gaduh. Hal itu, untuk memberi isyarat bahwa dalam wilayah pathet berikutnya, yaitu pathet 9 (sanga) sudah mulai terlihat permasalahan lakon.

Pocapan-pocapan yang dinarasikan Ki Nartasabda pada wilayah pathet 6 (nem) disesuaikan dengan iringan ulon gending grimingan gender dengan lagu atau notasi pada seleh 6 (nem) seperti berikut. ... 3216

Pocapan-pocapan yang dinarasikan Ki Nartasabda pada wilayah pathet 9 (sanga) menuansakan makna gelap, sunyi, sepi, gaduh, ribut, perang, dan mencekam. Dramatisasi lakon yang tercermin dalam makna pocapan-pocapan tersebut mulai tampak. Permasalahan lakon mulai dibangun dengan memunculkan berbagai konflik. Pocapan-pocapan itu dinarasikan Ki Nartasabdu nuksma dengan ulon gending grimingan gender yang jatuh pada seleh siji seperti berikut.

\section{.. . 5321}

Ki Nartasabda pada wilayah pathet manyura menarasikan pocapan-pocapan dalam nuansa makna ragu, bimbang, gelisah, panas, kacau balau, dan marah. Wilayah pathet manyura merupakan puncak dari dramatisasi lakon. Konflik lakon mencapai pada titik puncak dan akhirnya menuju peleraian. Peleraian yang dinarasikan Ki Nartasabda terlihat pada pocapan yang menuansakan makna ketidakberdayaan, pasrah, dan bahagia.

Suasana nuksma yang terlihat dalam pocapanpocapan di wilayah pathet manyura dapat dirasakan dengan nada lagu yang menyatu dengan ulon grimingan gender. Ulon grimingan gender itu jatuh pada seleh 3 (telu) seperti berikut.

. . . ! 653

Penyuaraan pocapan yang dinarasikan $\mathrm{Ki}$ Nartasabda adalah nuksma, artinya teknik dan lagu penyuaraan dapat sejiwa dengan isi serta suasana pocapan. Dalam menyuarakan pocapan, Ki Nartasabda mempertimbangkan ngeng atau ulon gendhing grimingan gender agar ritme, diksi, volume, dan nada lagu pocapan dapat menyatu dengan ulon grimingan gender.

Penarasian pocapan-pocapan disesuaikan dengan wilayah pathet. Dalam wilayah pathet 6 (nem), pada umumnya banyak dinarasikan pocapan yang bermakna datar. Hal itu, dikarenakan dalam wilayah pathet 6 (nem) dramatisasi lakon baru dibangun, artinya masih berkadar rendah. Pada wilayah pathet 9 (sanga) nuansa makna pocapan mulai agak meningkat, dramatisasi lakon dalam pathet ini mulai terlihat. Akan tetapi, pada wilayah pathet manyura akan banyak dinarasikan pocapan yang bernuansa panas atau klimaks. Hal itu, disebabkan dramatisasi lakon mencapai klimaksnya pada wilayah pathet manyura, hingga akhirnya menuju peleraian konflik. Nuansa makna dalam wilayah pathet 6 (nem) terkesan lebih tenang daripada wilayah pathet 9 (sanga), dan wilayah pathet manyura sebagai puncak penanjaan konflik mengarah pada akhir lakon. 
Ki Nartasabda adakalanya juga menggunakan iringan keprakan dan dhodhogan dalam menarasikan pocapan. Keprakan akan dipukul dengan irama nyisir dan apabila suasana pocapan menjelang klimaks maka keprakan akan dipukul dengan irama ngganter. Dhodhogan yang digunakan untuk mengiringi pocapan, yaitu mengggunakan irama banyu tumetes, cempala dipukulkan ke kothak secara tunggal dengan tekanan pelan, lirih, atau keras sesuai dengan suasana pocapan yang ditampilkan.

\section{Kepustakaan}

Djajasudarma, Fatimah. (1993). Semantik I Pengantar ke Arah Ilmu Makna. Bandung: Eresco.

Fokkema, D.W. \& Elrud Kunne-Ibsch. (1998). Teori Sastra Abad Kedua Puluh. Penerjemah J. Praptadiharja \& Kepler Silaban. Jakarta: PT Gramedia Pustaka Utama.

Harpawati, Tatik. (2005). "Kajian stilistika Pertunjukan Wayang Kulit Ki Nartasabda dalam Lakon Bima Sekti, Gathotkaca Sungging, dan Sawitri”. [Tesis]. Surakarta: STSI.

Murtiyoso, Bambang. (2007). Teori Pedalangan. Surakarta: ISI Press dan Saka Production.

Prasetya, Hanggar Budi. (2012). Pathêt: Ruang Bunyi dalam Karawitan Gaya Yogyakarta. Jurnal Seni \& Budaya Panggung, 22(1), 67.

Putra, I., Prasetya, H., \& -, S. (2014). Keprakan dalam Pertunjukan Wayang Gaya Yogyakarta: Studi Kasus Pementasan Ki Hadi Sugito. RESITAL : JURNAL SENI PERTUNJUKAN, 15(2), 190-201. doi:http:// dx.doi.org/10.24821/resital.v15i2.853

Santosa. (2002). “Makna Teks Musikal Gending-
Gending Karya Ki Nartasabda”. [Laporan Penelitian]. Surakarta: STSI.

Sudarko. (2013). Ragam Sulukan Wayang Kulit Purwa Gaya Yogyakarta: Studi Kasus Timbul Hadiprayitno, Hadi Sugito, dan Suparman. RESITAL : JURNAL SENI PERTUNJUKAN, 14(1). doi:http://dx.doi.org/10.24821/resital. v14i1.395

Sumanto. (1990). "Nartasabda Kehadirannya dalam Dunia Pedalangan sebuah Biografi". [Thesis]. UGM: Pascasarjana.

Sumanto. (2003). "Pathet Nggon Pedalangan Kuwi Apa? Studi Awal Makna Pathet dalam Pakeliran Tradisi Gaya Surakarta maupun Persepsi Seorang Dalang”. dalam Waridi (ed). Seni dalam Berbagai Wacana. Surakarata: STSI.

Sumanto. (2007). "Dasar-Dasar Garap Pakeliran" dalam Suyanto (ed). Teori Pedalangan. Surakarta: ISI Press dan Saka Production.

Suparno, Slamet. 2007. Seni Pedalangan Gagrag Surakarta. Surakarta: ISI Press.

Suyanto. (2007). Unsur-unsur Garap Pakeliran: Catur, Sabet, Sulukan, dan Musik Pakeliran. In Suyanto, Teori Pedalangan (pp. 1-5). Surakarta: ISI Press.

Suyoto, Haryono, T., \& Hastanto, S. (2015). Estetika Bawa dalam Karawitan Gaya Surakarta. Resital Jurnal Seni Pertunjukan, 39.

Teeuw. A. 1984. Sastra dan Ilmu Sastra. Jakarta: Pustaka Jaya.

\section{Informan}

Jaka Rianto (54 tahun). Dalang dan dosen Jurusan Pedalangan ISI Surakarta.

Sudarsono (56 tahun). Dalang dan dosen Jurusan Pedalangan ISI Surakarta. 